\section{Shift in Focus-To Explore the Role of the Endothelium in Kidney Disease}

\author{
Ilse Daehn* \\ Department of Medicine, The Icahn School of Medicine at Mount Sinai, \\ Madison Avenue, New York, USA
}

Chronic Kidney Disease (CKD) is estimated to affect over 13\% of US adults and is increasing in prevalence [1]. Most CKD cases are caused by glomerular diseases with progressive glomerulosclerosis lesions (www.usrds.org). In the last two decades podocytes have been intensely and productively investigated as central culprit in the evolution of segmental sclerosis lesions [2]. Thus, the 'podocyte depletion paradigm' places a critical role on irreversible loss of replication-deficient podocyte in the initiation of segmental sclerosis lesions and proteinuria [3]. Interestingly, the role of endothelial injury in glomerular disease remains relatively unexplored until recently [4-6], mainly because of the technical difficulties in isolating glomerular endothelial cells due to cell heterogeneity, lack of specific markers to identify organ specific endothelial cells, and challenges in maintaining long-term cultures.

Endothelial cell function is essential for maintenance of vascular homeostasis by releasing a variety of autocrine and paracrine factors that act locally to maintain vascular tone. On the other hand, nearly all vascular diseases arise from endothelial dysfunction. Glomerular endothelial cells are highly specialized with fenestrae and a luminal glycocalyx layer $[5,7,8]$, which contributes to the filtration barrier $[4,9]$. Recent studies have demonstrated that the absence (knockout) of endothelial Nitric Oxide Synthatase (eNOS) exacerbates renal injury and accelerates diabetic kidney damage [10,11]. In models of glomerulosclerosis, endothelial dysfunction has been recognized by our group and other groups to play a critical role in the development and progression of glomerular disease [12-14]. The role of endothelial cells in fibrosis is also gaining traction due to recent suggestion of Endothelial to Mesechymal Transition (EndoMT) and its contribution to fibrosis [15-17] further supporting a pivotal role for endothelial cell signaling and injury in renal fibrosis.

Although our current understanding of endothelial mediated events in kidney disease development and progression is still growing, endothelial dysfunction by mitochondrial oxidative stress, endothelial

*Corresponding author: Ilse Daehn, Department of Medicine, The Icahn School of Medicine at Mount Sinai, Madison Avenue, New York, USA, Tel: +1 2122414310; E-mail: ilse.daehn@mssm.edu

Citation: Daehn I (2016) Shift in Focus-To Explore the Role of the Endothelium in Kidney Disease. J Nephrol Renal Ther 2: 004.

Received: February 19, 2016; Accepted: February 24, 2016; Published: March 10, 2016 senescence, and nitric oxide reduction have emerged as a key pathogenic mechanism in kidney injury associated with diabetes, hypertension, obesity, dyslipidemia, and ageing $[18,19]$. Work in our laboratory has put forward a new working model for segmental sclerosis and propose endothelial cells to be key players in the progression of glomerular disease. We showed that perturbation of podocyte homeostasis (e.g., TGF- $\beta$, Adriamycin or microRNA dysregulation) can initiate mitochondrial oxidative stress and dysfunction in adjacent endothelial cells (via Edn1/Ednra). In response, dysfunctional endothelial cells feedback by mediating progressive damage and depletion of adjacent "activated" podocytes (via release of soluble factors) characteristic of progressive segmental sclerosis $[12,20]$. The exact mechanisms of how endothelial cells influence podocytes are currently subject of ongoing investigation. Moreover in diabetic kidney disease, were microvascular damage is a key event in diabetes-associated organ malfunction, glomerular endothelial cell injury may also contribute to early diabetic nephropathy as suggested by the increase of plasma von Willebrand factor observed in diabetic patients [21]. A reduced number of glomerular endothelial fenestrations in both type 1 and 2 diabetic patients has been also documented [22,23], and contrast to changes in podocyte morphology, endothelial abnormalities were found to be more closely associated with increasing urine albumin excretion. The endothelial surface layer (glycocalix and endothelial cell coat), provides an important barrier to protein permeability and studies have demonstrated a severe reduction of the endothelial glycocalyx in type 2 diabetic patients and in animal models [24,25]. Hence studies from structural, molecular and functional viewpoints now demonstrate that endothelial cell function plays a critical role in the susceptibility and pathogenesis of progressive diabetic nephropathy, and challenge the notion that podocyte injury and loss is the primary event in nephropathy as recently suggested [26,27].

A vast amount of research has been devoted to understanding the mechanisms and pathogenesis of glomerular and tubular disease from the epithelial cell point of view, and unfortunately this knowledge has not led to new effective treatments. Intriguingly, RAS blockade has been firmly established as the 'renoprotective' intervention of choice to reduce proteinuria and retard progression of CKD [28]. However, despite the widespread clinical use of RAS blockade, the prevalence of advanced stages of CKD continues to increase [29]. Hence, new therapies aimed at preventing progression of CKD constitute a hugely important unmet need. There is now and increased interest and potential shift in focus to explore the role of the endothelium in kidney disease as a potential key player in development and progression of the disease. Given that endothelial cells may influence disease progression, one could consider the possibility that drugs targeted at preventing endothelial dysfunction could be useful in preventing renal damage. However as we learned from recent efforts, focusing on individual cells as responsible for entire organ damage may be counterproductive. More information is warranted to understand the relationships and crosstalk between the glomerular endothelium, epithelium, mesangium, parietal epithelial cell and fibroblasts while acknowledging that kidney damage can be 
influenced by changes in blood pressure, hyperglycemia as well as consideration to other factors such as race, socioeconomic status, obesity, dyslipidemia and other unknown factors.

Finally, as investigators we could consider employing new paradigms where we recognize that the "sum of the contributions of each cell type" as part of an integrated functional yet complex system [30]. These efforts will stimulate discoveries and novel approaches for intervention.

\section{References}

1. Coresh J, Selvin E, Stevens LA, Manzi J, Kusek JW, et al. (2007) Prevalence of chronic kidney disease in the United States. JAMA 298: 2038-2047.

2. Kriz W, Gretz N, Lemley KV (1998) Progression of glomerular diseases: is the podocyte the culprit? Kidney Int 54: 687-697.

3. Wiggins RC (2007) The spectrum of podocytopathies: a unifying view of glomerular diseases. Kidney Int 71: 1205-1214.

4. Haraldsson B, Nyström J (2012) The glomerular endothelium: new insights on function and structure. Curr Opin Nephrol Hypertens 21: 258-263.

5. Ballermann BJ (2007) Contribution of the endothelium to the glomerular permselectivity barrier in health and disease. Nephron Physiol 106: 19-25.

6. Schlöndorff D, Banas B (2009) The mesangial cell revisited: no cell is an island. J Am Soc Nephrol 20: 1179-1187.

7. Haraldsson B, Jeansson M (2009) Glomerular filtration barrier. Curr Opin Nephrol Hypertens 18: 331-335.

8. Fogo $A B$, Kon $V(2010)$ The glomerulus--a view from the inside--the endothelial cell. Int J Biochem Cell Biol 42: 1388-1397.

9. Jeansson M, Björck K, Tenstad O, Haraldsson B (2009) Adriamycin alters glomerular endothelium to induce proteinuria. J Am Soc Nephrol 20: 114-122.

10. Heeringa $\mathrm{P}$, van Goor H, Itoh-Lindstrom $\mathrm{Y}$, Maeda N, Falk RJ, et al. (2000) Lack of endothelial nitric oxide synthase aggravates murine accelerated anti-glomerular basement membrane glomerulonephritis. Am J Pathol 156: 879-888.

11. Zhao HJ, Wang S, Cheng H, Zhang MZ, Takahashi T, et al. (2006) Endothelial nitric oxide synthase deficiency produces accelerated nephropathy in diabetic mice. J Am Soc Nephrol 17: 2664-2669.

12. Daehn I, Casalena G, Zhang T, Shi S, Fenninger F, et al. (2014) Endothelial mitochondrial oxidative stress determines podocyte depletion in segmental glomerulosclerosis. J Clin Invest 124: 1608-1621.

13. Haraldsson B, Nyström J, Deen WM (2008) Properties of the glomerular barrier and mechanisms of proteinuria. Physiol Rev 88: 451-487.

14. Sun YB, Qu X, Zhang X, Caruana G, Bertram JF, et al. (2013) Glomerular endothelial cell injury and damage precedes that of podocytes in adriamycin-induced nephropathy. PLoS One 8: 55027.
15. Kizu A, Medici D, Kalluri R (2009) Endothelial-mesenchymal transition as a novel mechanism for generating myofibroblasts during diabetic nephropathy. Am J Pathol 175: 1371-1373.

16. Zeisberg EM, Potenta SE, Sugimoto H, Zeisberg M, Kalluri R (2008) Fibroblasts in kidney fibrosis emerge via endothelial-to-mesenchymal transition. J Am Soc Nephrol 19: 2282-2287.

17. Xavier S, Vasko R, Matsumoto K, Zullo JA, Chen R, et al. (2015) Curtailing endothelial TGF- $\beta$ signaling is sufficient to reduce endothelial-mesenchymal transition and fibrosis in CKD. J Am Soc Nephrol 26: 817-829.

18. Widlansky ME, Gutterman DD (2011) Regulation of endothelial function by mitochondrial reactive oxygen species. Antioxid Redox Signal 15: 1517-1530.

19. Tang X, Luo YX, Chen HZ, Liu DP (2014) Mitochondria, endothelial cell function, and vascular diseases. Front Physiol 5: 175.

20. Casalena G, Bottinger E, Daehn I (2015) TGF $\beta$-Induced Actin Cytoskeleton Rearrangement in Podocytes is Associated with Compensatory Adaptation of Mitochondrial Energy Metabolism. Nephron 131: 278-284.

21. Lamberton RP, Goodman AD, Kassoff A, Rubin CL, Treble DH, et al. (1984) Von Willebrand factor (VIII R:Ag), fibronectin, and insulin-like growth factors I and II in diabetic retinopathy and nephropathy. Diabetes 33: 125-129.

22. Toyoda M, Najafian B, Kim Y, Caramori ML, Mauer M (2007) Podocyte detachment and reduced glomerular capillary endothelial fenestration in human type 1 diabetic nephropathy. Diabetes 56: 2155-2160.

23. Weil EJ, Lemley KV, Mason CC, Yee B, Jones LI, et al (2012) Podocyte detachment and reduced glomerular capillary endothelial fenestration promote kidney disease in type 2 diabetic nephropathy. Kidney Int 82: 1010-1017.

24. Broekhuizen LN, Lemkes BA, Mooij HL, Meuwese MC, Verberne H, et al. (2010) Effect of sulodexide on endothelial glycocalyx and vascular permeability in patients with type 2 diabetes mellitus. Diabetologia 53: 2646-2655.

25. Singh A, Fridén V, Dasgupta I, Foster RR, Welsh GI, et al. (2011) High glucose causes dysfunction of the human glomerular endothelial glycocalyx. Am J Physiol Renal Physiol 300: 40-48.

26. Nakagawa T, Tanabe K, Croker BP, Johnson RJ, Grant MB, et al. (2011) Endothelial dysfunction as a potential contributor in diabetic nephropathy. Nat Rev Nephrol 7: 36-44.

27. Fu J, Lee K, Chuang PY, Liu Z, He JC (2015) Glomerular endothelial cell injury and cross talk in diabetic kidney disease. Am J Physiol Renal Physiol 308: $287-297$.

28. Taal MW, Brenner BM (2002) Combination ACEI and ARB therapy: additional benefit in renoprotection? Curr Opin Nephrol Hypertens 11: 377-381.

29. National Institutes of Health (2011) United States Renal Data System 2011 Annual Data Report: Atlas of Chronic Kidney Disease and End-Stage Renal Disease in the United States. National Institute of Diabetes and Digestive and Kidney Diseases, National Institutes of Health, Bethesda, Maryland, USA.

30. Schlöndorff D (2014) Putting the glomerulus back together: per aspera ad astra ("a rough road leads to the stars"). Kidney Int 85: 991-998. 